\title{
nephron

\section{Association of Hypo- and Hyperkalemia with Disease Progression and Mortality in Males with Chronic Kidney Disease: The Role of Race}

\author{
John Hayes ${ }^{a}$ Kamyar Kalantar-Zadeh ${ }^{b, c}$ Jun L. Lu ${ }^{d} \quad$ Sharon Turban $^{f}$ \\ John E. Anderson ${ }^{f}$ Csaba P. Kovesdy ${ }^{a}$ e

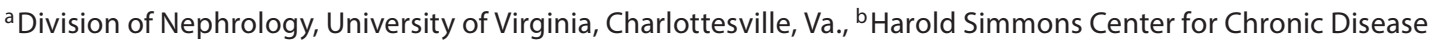 \\ Research and Epidemiology, and 'Division of Nephrology and Hypertension, Los Angeles Biomedical Research \\ Institute at Harbor-UCLA Medical Center, Torrance, Calif., ${ }^{d}$ Salem Research Institute, e Division of Nephrology, \\ Salem Veterans Affairs Medical Center, Salem, Va., and fDivision of Nephrology, Johns Hopkins University, \\ Baltimore, Md., USA
}

\section{Key Words}

Serum potassium - Chronic kidney disease - Mortality •

Race $\cdot$ Glomerular filtration rate

\begin{abstract}
Background/Aims: Abnormal serum potassium is associated with higher mortality in dialysis patients, but its impact on outcomes in predialysis chronic kidney disease (CKD) is less clear. Furthermore, blacks with normal kidney function have lower urinary potassium excretion, but it is unclear if such differences have a bearing on race-associated outcomes in CKD. Methods: We studied predialysis mortality and slopes of estimated glomerular filtration rate, eGFR) associated with serum potassium in 1,227 males with CKD. Mortality was examined in time-dependent Cox models, and slopes of eGFR in linear mixed effects models with adjustments for case mix and laboratory values. Results: Both hypo- and hyperkalemia were associated with mortality overall and in 933 white patients, but in 294 blacks hypokalemia was a stronger death predictor. Hypokalemia was associated with loss of kidney function independent of race: a $1 \mathrm{mEq} / \mathrm{l}$ lower potassium was associated with an adjusted difference in slopes of eGFR of $-0.13 \mathrm{ml} /$ $\mathrm{min} / 1.73 \mathrm{~m}^{2} /$ year (95\% Cl: -0.20 to -0.07 ), $\mathrm{p}<0.001$. Conclusion: Hypo- and hyperkalemia are associated with higher
\end{abstract}

\section{KARGER}

Fax +4161306 1234

E-Mail karger@karger.ch

www.karger.com (c) 2011 S. Karger AG, Basel

Accessible online at: www.karger.com/nec mortality in CKD patients. Blacks appear to better tolerate higher potassium than whites. Hypokalemia is associated with faster CKD progression independent of race. Hyperkalemia management may warrant race-specific consideration, and hypokalemia correction may slow CKD progression.

$$
\begin{array}{r}
\text { This is a work of the US Government and is not subject to } \\
\text { copyright protection in the USA. Foreign copyrights may apply. } \\
\text { Published by S. Karger AG, Basel }
\end{array}
$$

\section{Introduction}

Individuals with chronic kidney disease (CKD) and especially those with end-stage renal disease (ESRD) experience abnormal potassium homeostasis by virtue of their lower kidney function and various therapeutic interventions that can lead to hypo- or hyperkalemia [1]. Abnormal potassium values have been associated with mortality in dialysis patients $[2,3]$, and more recently also in patients with various degrees of non-dialysis-dependent CKD (NDD-CKD) [4]. Besides the short-term arrhythmogenic effects of hypo- and hyperkalemia, potassium may also have an indirect impact on clinical outcomes through inflammation, oxidative stress, renal interstitial fibrosis, vascular biology and blood pressure [5-10]. The role of potassium is even more complicated in patients with NDD-CKD, in whom abnormal potassium 
levels may unduly hinder the administration of medications with benefits on clinical outcomes such as angiotensin-converting enzyme inhibitors (ACEI) or angiotensin receptor blockers (ARBs).

Racial differences in potassium intake and excretion have been implicated as a potential mechanism, whereby blacks experience more severe hypertension, cardiovascular and renal disease in the general population [11-17]. While black patients are overrepresented in ESRD relative to their proportions in the general population [18, 19], mortality in blacks with ESRD and NDD-CKD is paradoxically lower compared to whites [20,21]. It is unclear how differences in potassium excretion or intake in black and white individuals with moderate and advanced NDD-CKD affect race-specific clinical outcomes in these patients.

We examined overall and race-specific all-cause predialysis mortality and progression of CKD as a function of serum potassium levels in a historical cohort of male patients with moderate and advanced NDD-CKD.

\section{Materials and Methods}

\section{Study Population and Data Collection}

We examined all 1,259 patients referred for evaluation and treatment of NDD-CKD to the Nephrology Department at Salem Veteran Affairs Medical Center (VAMC) between January 1, 1990, and June 30, 2007, and followed them until April 1, 2009. Nine females, 6 patients whose race was other than white or black, and 17 patients with no serum potassium measurements were excluded, with the final study population consisting of 1,227 patients.

Baseline characteristics recorded at the time of the patients' initial evaluation in the Nephrology Clinic were extracted retrospectively, including demographic and anthropometric characteristics, comorbid conditions including the Charlson comorbidity index (CCI), and laboratory results, as detailed elsewhere [22, 23]. Followup clinical and laboratory data were time updated during the entire follow-up period, and included all medication use data, body mass index (BMI), blood pressure and all the outpatient laboratory parameters including serum creatinine and potassium values.

Medication prescriptions relevant to serum potassium levels including that of ACEI/ARB, diuretics, potassium supplements, non-steroidal anti-inflammatory drugs (NSAIDs) and betablockers were assessed from pharmacy records over the entire follow-up period. Glomerular filtration rate (GFR) was estimated using the abbreviated equation developed for the Modification of Diet in Renal Disease Study [24]. All the biochemical measurements were performed in a single laboratory at the Salem VAMC. Serum creatinine was measured by an enzymatic method.

\section{Statistical Analyses}

Data points that were missing throughout the follow-up period for CCI ( $1 \%$ missing), BMI (14\%), serum albumin (0.8\%), phosphorus $(1.7 \%)$, blood cholesterol $(2 \%)$, hemoglobin $(0.3 \%)$, white blood cell count (WBC, $0.8 \%)$, percent lymphocytes in WBC
(0.9\%) and 24-hour urine protein (3.2\%) were imputed using multivariable regression with all the other covariate serving as independent variables. Active smoking (5\%) and NSAID use (11\%) were analyzed as categorical variables with the creation of a dummy category corresponding to missing status.

The starting time for outcome analyses was the date of the first encounter in the Nephrology Clinic. Patients were considered lost to follow-up if no contact was documented with them for more than 6 months, and they were censored at the date of the last documented contact. Outcome measures were pre-dialysis all-cause mortality (ascertained from VA electronic records), and the slopes of estimated GFR (eGFR) vs. time.

All analyses were performed in the overall sample and separately in subgroups divided by race (whites and blacks). The associations of time-varying serum potassium levels with all-cause mortality were evaluated in time-dependent Cox models with adjustment for potential confounders. The change in eGFR from baseline until death, start of dialysis or loss of follow-up (whichever occurred first) was studied in 1,160 patients who had at least 4 serum creatinine measurements (median: 18 measurements, range: $4-135$ ). The association between serum potassium and the slopes of eGFR was examined in generalized linear mixed effects models by using a two-stage model formulation [25].

Multivariable models were adjusted for covariates that were different at baseline between the groups with different serum potassium level and also for covariates that could be expected to act as confounders based on theoretical considerations. All multivariable models were thus adjusted sequentially for age, race, CCI, diabetes mellitus (DM), cardiovascular disease, BMI, smoking status, eGFR, serum albumin, bicarbonate, calcium, phosphorus, blood hemoglobin, 24-hour urine protein, and the use of ACEI/ ARB, diuretics, potassium supplements, NSAIDs and beta-blockers. All independent covariates were treated as time-dependent variables (if appropriate). As blood pressure could be in the path of causality of the association between potassium and outcomes, this variable was only included in multivariable models in sensitivity analyses. The expected non-linearity of the association between potassium and mortality was explored first by including polynomial terms for potassium. In models where a significant non-linear association was shown, the shape of the association was further explored by using a multivariable fractional polynomial approach of model building transferred to regression splines, adjusting linearly for covariates [26]. For descriptive analyses, serum potassium was categorized according to its median serum level and the lower and upper limit of its normal range in the measuring laboratory $(<3.6,3.6-4.5,4.51-5.3$ and $>5.3 \mathrm{mEq} / \mathrm{l})$. In order to gain practical information on serum potassium cutoffs relevant to the studied outcomes, we also tested various other serum potassium levels to define hypo- and hyperkalemia as categories that are associated with increased risk for clinical outcomes.

Sensitivity analyses were performed by analyzing associations of serum potassium with overall (pre- and post-dialysis) mortality, by adjusting for systolic and diastolic blood pressure, by including medications in an intent-to-treat fashion, by using only non-imputed values of independent variables and by restricting analyses to a more contemporary cohort of patients enrolled after January 1,2001 . To explore the possibility that discrepant outcomes associated with hyperkalemia in white and black patients may have been an artifact due to the low number of blacks with hyperkalemia, we also examined the association of hyperkalemia with mortality in a matched cohort of white patients who were 
Table 1. Baseline characteristics of 1,227 CKD patients overall and divided into categories of baseline serum potassium levels

\begin{tabular}{|c|c|c|c|c|c|c|}
\hline & \multirow{2}{*}{$\begin{array}{l}\text { All patients } \\
(\mathrm{n}=1,227)\end{array}$} & \multicolumn{4}{|c|}{ Serum potassium (mEq/l) } & \multirow{2}{*}{$\begin{array}{l}\mathrm{p} \text { for } \\
\text { trend }\end{array}$} \\
\hline & & $<3.6(\mathrm{n}=39)$ & $3.6-4.5(\mathrm{n}=557)$ & $4.51-5.3(\mathrm{n}=536)$ & $>5.3(\mathrm{n}=95)$ & \\
\hline Age, years & $68 \pm 11$ & $65.6 \pm 10.5$ & $68.1 \pm 11.2$ & $69.0 \pm 10.4$ & $68.2 \pm 11.0$ & 0.13 \\
\hline African-Americans & $294(24)$ & $12(31)$ & $151(27)$ & $107(20)$ & $24(25)$ & 0.04 \\
\hline eGFR, $\mathrm{ml} / \mathrm{s} / 1.73 \mathrm{~m}^{2}$ & $0.62 \pm 0.23$ & $0.70 \pm 0.35$ & $0.67 \pm 0.30$ & $0.60 \pm 0.27$ & $0.48 \pm 0.18$ & $<0.001$ \\
\hline \multicolumn{7}{|l|}{ Comorbid states } \\
\hline $\mathrm{DM}$ & $672(55)$ & $17(44)$ & $293(53)$ & $305(57)$ & $57(60)$ & 0.03 \\
\hline ASCVD & $696(57)$ & $25(64)$ & $306(55)$ & $302(56)$ & $63(66)$ & 0.3 \\
\hline CCI & $2.5 \pm 1.7$ & $2.5 \pm 1.8$ & $2.3 \pm 1.7$ & $2.5 \pm 1.7$ & $2.9 \pm 1.7$ & 0.008 \\
\hline Smoking & $297(25)$ & $12(32)$ & $131(25)$ & $124(24)$ & $30(33)$ & 0.6 \\
\hline \multicolumn{7}{|l|}{ Medications } \\
\hline ACEI/ARB use & $722(59)$ & $24(62)$ & $331(59)$ & $306(57)$ & $61(64)$ & 0.9 \\
\hline Diuretics & $799(65)$ & $33(85)$ & $360(65)$ & $338(63)$ & $68(72)$ & 0.79 \\
\hline Potassium supplements & $192(16)$ & $20(51)$ & $105(19)$ & $57(11)$ & $10(11)$ & $<0.001$ \\
\hline NSAIDs & $275(26)$ & $10(29)$ & $125(26)$ & $120(26)$ & $20(24)$ & 0.76 \\
\hline Beta-blockers & $562(46)$ & $24(62)$ & $254(46)$ & $244(46)$ & $40(42)$ & 0.2 \\
\hline BMI & $29.3 \pm 5.9$ & $29.7 \pm 5.4$ & $29.6 \pm 5.9$ & $29.3 \pm 5.8$ & $27.6 \pm 6.5$ & 0.02 \\
\hline $\mathrm{sBP}, \mathrm{mm} \mathrm{Hg}$ & $150 \pm 26$ & $153 \pm 28$ & $150 \pm 26$ & $148 \pm 26$ & $150 \pm 26$ & 0.3 \\
\hline $\mathrm{dBP}, \mathrm{mm} \mathrm{Hg}$ & $74 \pm 15$ & $78 \pm 17$ & $76 \pm 15$ & $73 \pm 15$ & $71 \pm 14$ & $<0.001$ \\
\hline Serum potassium, $\mathrm{mEq} / \mathrm{l}$ & $4.5 \pm 0.6$ & $3.2 \pm 0.3$ & $4.1 \pm 0.2$ & $4.8 \pm 0.2$ & $5.7 \pm 0.3$ & \\
\hline Albumin, $\mathrm{g} / \mathrm{l}$ & $36 \pm 5$ & $37 \pm 4$ & $36 \pm 5$ & $36 \pm 5$ & $35 \pm 5$ & 0.3 \\
\hline Cholesterol, mmol/l & $4.91 \pm 1.45$ & $4.65 \pm 1.09$ & $4.91 \pm 1.47$ & $4.99 \pm 1.47$ & $4.81 \pm 1.27$ & 0.6 \\
\hline Bicarbonate, mmol/l & $25.7 \pm 3.4$ & $27.8 \pm 3.3$ & $26.2 \pm 3.3$ & $25.3 \pm 3.3$ & $24.0 \pm 4.0$ & $<0.001$ \\
\hline Calcium, mmol/l & $2.30 \pm 0.15$ & $2.30 \pm 0.12$ & $2.30 \pm 0.15$ & $2.30 \pm 0.15$ & $2.25 \pm 0.17$ & 0.4 \\
\hline Phosphorus, mmol/l & $1.23 \pm 0.26$ & $1.16 \pm 0.19$ & $1.19 \pm 0.23$ & $1.26 \pm 0.26$ & $1.36 \pm 0.29$ & $<0.001$ \\
\hline Blood Hgb, g/l & $127 \pm 19$ & $130 \pm 19$ & $129 \pm 19$ & $125 \pm 18$ & $119 \pm 19$ & $<0.001$ \\
\hline WBC, $1,000 / \mathrm{mm}^{3}$ & $7.6 \pm 2.3$ & $7.8 \pm 2.0$ & $7.5 \pm 2.3$ & $7.6 \pm 2.2$ & $7.9 \pm 2.8$ & 0.3 \\
\hline Lymphocytes, \% WBC & $23.2 \pm 8.5$ & $23.4 \pm 8.4$ & $23.1 \pm 8.5$ & $23.7 \pm 8.6$ & $21.7 \pm 8.0$ & 0.7 \\
\hline Proteinuria, $\mathrm{mg} / 24 \mathrm{~h}$ & $741(680-808)$ & $616(358-1,059)$ & $752(660-856)$ & $710(624-809)$ & $945(695-1,286)$ & 0.4 \\
\hline
\end{tabular}

Data are presented as means $\pm \mathrm{SD}$, number (\% of total) or geometric means $(95 \% \mathrm{CI})$. ASCVD = Atherosclerotic cardiovascular disease; $\mathrm{sBP}=$ systolic blood pressure; $\mathrm{dBP}=$ diastolic blood pressure; $\mathrm{Hgb}=$ hemoglobin; $\mathrm{WBC}=$ white blood cell count. Comparisons were made by $\chi^{2}$ test for linear trend between the categories of patients with different potassium levels.

paired with black patients based on their serum potassium levels. In order to address the possibility that early deaths in cohort participants with abnormal serum potassium levels may have obscured progressive loss of kidney function and thus may have biased the slope estimates, we have also performed sensitivity analyses by examining slopes of eGFR in a subgroup of 259 patients who reached ESRD. p values of less than 0.05 were considered significant. Statistical analyses were performed using Stata statistical software v11 (StataCorp, College Station, Tex., USA). The study protocol was approved by the Research and Development Committee at the Salem VAMC.

\section{Results}

The mean $( \pm S D)$ age of the cohort at baseline was $68 \pm$ 11 years, $24 \%$ of patients were black, and the mean ( \pm SD) eGFR was $37 \pm 17 \mathrm{ml} / \mathrm{min} / 1.73 \mathrm{~m}^{2}$. Most patients had
CKD stages 3 (55\%) and 4 (31\%), with few patients categorized as CKD stage 1 (1\%), 2 (8\%) and 5 (5\%). The mean $( \pm \mathrm{SD})$ baseline serum potassium was $4.5 \pm 0.6 \mathrm{mEq} / \mathrm{l}$. Throughout the follow-up period, there were 230 patients (19\%) who experienced at least one serum potassium $<3.6$ $\mathrm{mEq} / \mathrm{l}$ [169 (18\%) whites and 61 (21\%) blacks], and 515 (42\%) who experienced at least one serum potassium $>5.3$ $\mathrm{mEq} / \mathrm{l}$ [397 (43\%) whites and 118 (40\%) blacks]. Patients had a median of 20 follow-up assessments (interquartile range: $12-33)$. Seven hundred and fifty-two patients (61\%) were enrolled in the study after January 1, 2001. A total of 486 patients died before the initiation of dialysis (mortality rate: 118/1,000 patient-years, 95\% confidence interval, CI: 108-129) during a median follow-up of 2.7 years. Thirty-eight patients (3\%) were lost to follow-up, and their characteristics were not significantly different (data not shown). 
Table 2. Baseline characteristics of 1,227 CKD outpatients stratified by race

\begin{tabular}{|c|c|c|c|}
\hline & $\begin{array}{l}\text { Whites } \\
(n=933)\end{array}$ & $\begin{array}{l}\text { African- } \\
\text { Americans } \\
(\mathrm{n}=294)\end{array}$ & $\begin{array}{l}\mathrm{p} \\
\text { value }\end{array}$ \\
\hline Age, years & $69.5 \pm 10.2$ & $65.0 \pm 12.2$ & $<0.0001$ \\
\hline $\mathrm{DM}$ & $510(55)$ & $162(55)$ & 0.9 \\
\hline ASCVD & $569(61)$ & $127(43)$ & $<0.001$ \\
\hline Smoking & $207(23)$ & $90(33)$ & 0.002 \\
\hline CCI & $2.5 \pm 1.7$ & $2.5 \pm 1.8$ & 0.8 \\
\hline ACEI/ARB use & $705(76)$ & $227(77)$ & 0.6 \\
\hline Diuretics & $723(77)$ & $225(77)$ & 0.7 \\
\hline Potassium supplements & $363(39)$ & $119(40)$ & 0.6 \\
\hline NSAIDs & $354(38)$ & $122(41)$ & 0.27 \\
\hline Beta-blockers & $644(69)$ & $188(64)$ & 0.1 \\
\hline BMI & $29.4 \pm 5.8$ & $29.2 \pm 6.1$ & 0.3 \\
\hline $\mathrm{sBP}, \mathrm{mm} \mathrm{Hg}$ & $148 \pm 26$ & $155 \pm 25$ & 0.0001 \\
\hline $\mathrm{dBP}, \mathrm{mm} \mathrm{Hg}$ & $72 \pm 15$ & $82 \pm 15$ & $<0.0001$ \\
\hline Serum potassium, $\mathrm{mEq} / \mathrm{l}$ & $4.5 \pm 0.6$ & $4.4 \pm 0.6$ & 0.005 \\
\hline $\mathrm{eGFR}, \mathrm{ml} / \mathrm{s} / 1.73 \mathrm{~m}^{2}$ & $0.63 \pm 0.28$ & $0.58 \pm 0.28$ & 0.007 \\
\hline Serum albumin, g/l & $36 \pm 5$ & $35 \pm 5$ & 0.02 \\
\hline Serum cholesterol, mmol/l & $4.89 \pm 1.42$ & $5.04 \pm 1.53$ & 0.17 \\
\hline Serum bicarbonate, $\mathrm{mmol} / \mathrm{l}$ & $25.8 \pm 3.4$ & $25.1 \pm 3.4$ & 0.004 \\
\hline Serum calcium, $\mathrm{mmol} / \mathrm{l}$ & $2.27 \pm 0.12$ & $2.30 \pm 0.15$ & 0.4 \\
\hline Serum phosphorus, mmol/l & $1.23 \pm 0.26$ & $1.23 \pm 0.26$ & 0.9 \\
\hline Blood Hgb, g/l & $128 \pm 19$ & $123 \pm 19$ & $<0.0001$ \\
\hline Blood WBC, $1,000 / \mathrm{mm}^{3}$ & $7.8 \pm 2.2$ & $7.1 \pm 2.4$ & $<0.0001$ \\
\hline Blood lymphocytes, \%WBC & $22.3 \pm 7.9$ & $26.2 \pm 9.6$ & $<0.0001$ \\
\hline Proteinuria, mg/24h & $\begin{array}{l}702 \\
(634-777)\end{array}$ & $\begin{array}{l}881 \\
(750-1,034)\end{array}$ & 0.03 \\
\hline
\end{tabular}

Data are presented as means $\pm \mathrm{SD}$, number (\% of total) or geometric means $(95 \% \mathrm{CI})$. Comparisons were made by t test or $\chi^{2}$ test.

Baseline characteristics in patients divided by categories of serum potassium are shown in table 1. Patients with higher baseline serum potassium were more likely to be white and diabetic and less likely to receive potassium supplements, and had lower BMI, diastolic blood pressure, eGFR, serum bicarbonate and blood hemoglobin, and higher CCI and serum phosphorus.

Baseline characteristics of patients divided by their race are shown in table 2. Black patients were younger, more likely to be active smokers and less likely to have cardiovascular disease, had lower eGFR, serum albumin, bicarbonate and blood hemoglobin and WBC levels, and higher blood pressure, percent lymphocytes in WBC and 24 -hour urine protein. Serum potassium was significantly higher in white patients: $4.5 \pm 0.6$ vs. $4.4 \pm 0.6 \mathrm{mEq} / \mathrm{l}$ in blacks $(\mathrm{p}<0.01)$.

Potassium and CKD Outcomes
Table 3. Unadjusted and multivariable adjusted correlation coefficients of baseline potassium levels with other relevant baseline variables

\begin{tabular}{|c|c|c|}
\hline & Unadjusted & Adjusted \\
\hline Age & $0.06^{*}$ & -0.01 \\
\hline African-American race & $-0.08^{* *}$ & $-0.08^{*}$ \\
\hline \multicolumn{3}{|l|}{ Comorbid states } \\
\hline $\mathrm{DM}$ & $0.09^{* *}$ & $0.10^{* *}$ \\
\hline ASCVD & 0.02 & 0.01 \\
\hline CCI & $0.09^{* *}$ & -0.01 \\
\hline History of smoking & -0.01 & -0.01 \\
\hline BMI & $-0.10^{* *}$ & -0.06 \\
\hline sBP & $-0.06^{*}$ & -0.03 \\
\hline $\mathrm{dBP}$ & $-0.14^{* * *}$ & $-0.07^{*}$ \\
\hline \multicolumn{3}{|l|}{ Medications: } \\
\hline ACEI/ARB & 0.01 & -0.01 \\
\hline Diuretics & -0.02 & 0.04 \\
\hline Potassium supplements & $-0.20 * * *$ & $-0.20 * * *$ \\
\hline NSAIDs & -0.04 & 0.02 \\
\hline Beta-blockers & -0.04 & -0.06 \\
\hline eGFR & $-0.20 * * *$ & $-0.08^{*}$ \\
\hline Serum albumin & -0.03 & -0.01 \\
\hline Bicarbonate & $-0.25^{* * *}$ & $-0.15^{* * *}$ \\
\hline Calcium & -0.01 & $0.07^{*}$ \\
\hline Phosphorus & $0.20 * * *$ & $0.13^{* *}$ \\
\hline Blood hemoglobin & $-0.18^{* * *}$ & $-0.08^{*}$ \\
\hline Proteinuria & 0.01 & -0.03 \\
\hline
\end{tabular}

Multivariable adjustments were performed for all the listed covariates.

${ }^{*} \mathrm{p}<0.05,{ }^{* *} \mathrm{p}<0.01,{ }^{* * *} \mathrm{p}<0.001$ ( $\mathrm{r}$ values $\geq 0.10$ are in bold).

Table 3 shows unadjusted and multivariable adjusted correlation coefficients of baseline serum potassium levels with other relevant variables. Lower serum potassium was significantly associated with black race, administration of potassium supplements, higher DBP, eGFR, serum bicarbonate and hemoglobin levels, and higher serum potassium was associated with higher phosphorus and the presence of DM.

The association of serum potassium with all-cause mortality in the overall patient population was significant and non-linear ( $\mathrm{p}<0.001$ for the quadratic term), with regression splines showing an increase in mortality in association with both high and low serum potassium levels (fig. 1). The association between serum potassium and mortality varied according to the patients' race (fig. 2). Increased mortality was seen in association with abnormally low serum potassium levels in both white and black pa-

Nephron Clin Pract 2012;120:c8-c16 
Fig. 1. Multivariable adjusted log hazards (solid line) and 95\% CI (dashed lines) of all-cause predialysis mortality associated with serum potassium levels in the entire study population $(n=1,227)$. Associations were examined in time-varying Cox models adjusted for age, race, smoking status, CCI, DM, cardiovascular disease, BMI, the use of ACEI, ARBs, diuretics, potassium supplements, NSAIDs, beta-blockers, eGFR, serum albumin, bicarbonate, calcium, phosphorus, blood hemoglobin, and 24-hour urine protein.

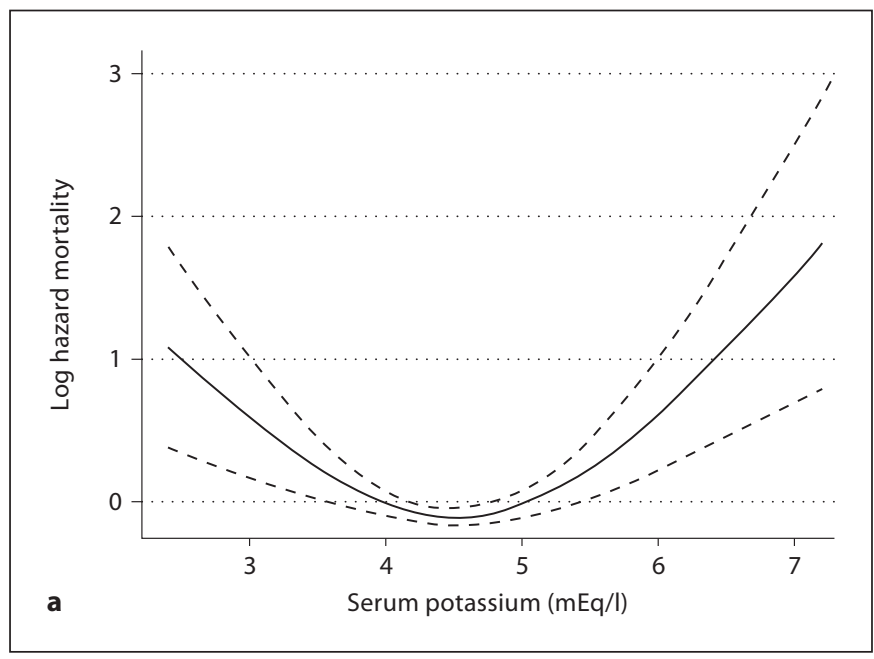

Fig. 2. Multivariable adjusted log hazards (solid lines) and 95\% CI (dashed lines) of all-cause predialysis mortality associated with serum potassium levels in white $(n=933 ; a)$ and black $(n=294$; b) patients. Associations were examined in separate time-varying Cox models adjusted for age, race, smoking status, CCI, DM, car-

tients, and with abnormally high serum potassium levels in white patients, but no significant association between higher serum potassium and mortality was present in black patients. Categorical analyses indicated significantly increased mortality associated with serum potassium $<3.8$ $\mathrm{mEq} / \mathrm{l}$ in whites and $<3.7 \mathrm{mEq} / \mathrm{l}$ in blacks (fig. 3) and with serum potassium $>5.5 \mathrm{mEq} / \mathrm{l}$ in white patients, but not black patients (fig. 4). The discrepant risk of mortality associated with a serum potassium $>5.5 \mathrm{mEq} / \mathrm{l}$ in whites and blacks persisted when including only 258 white patients
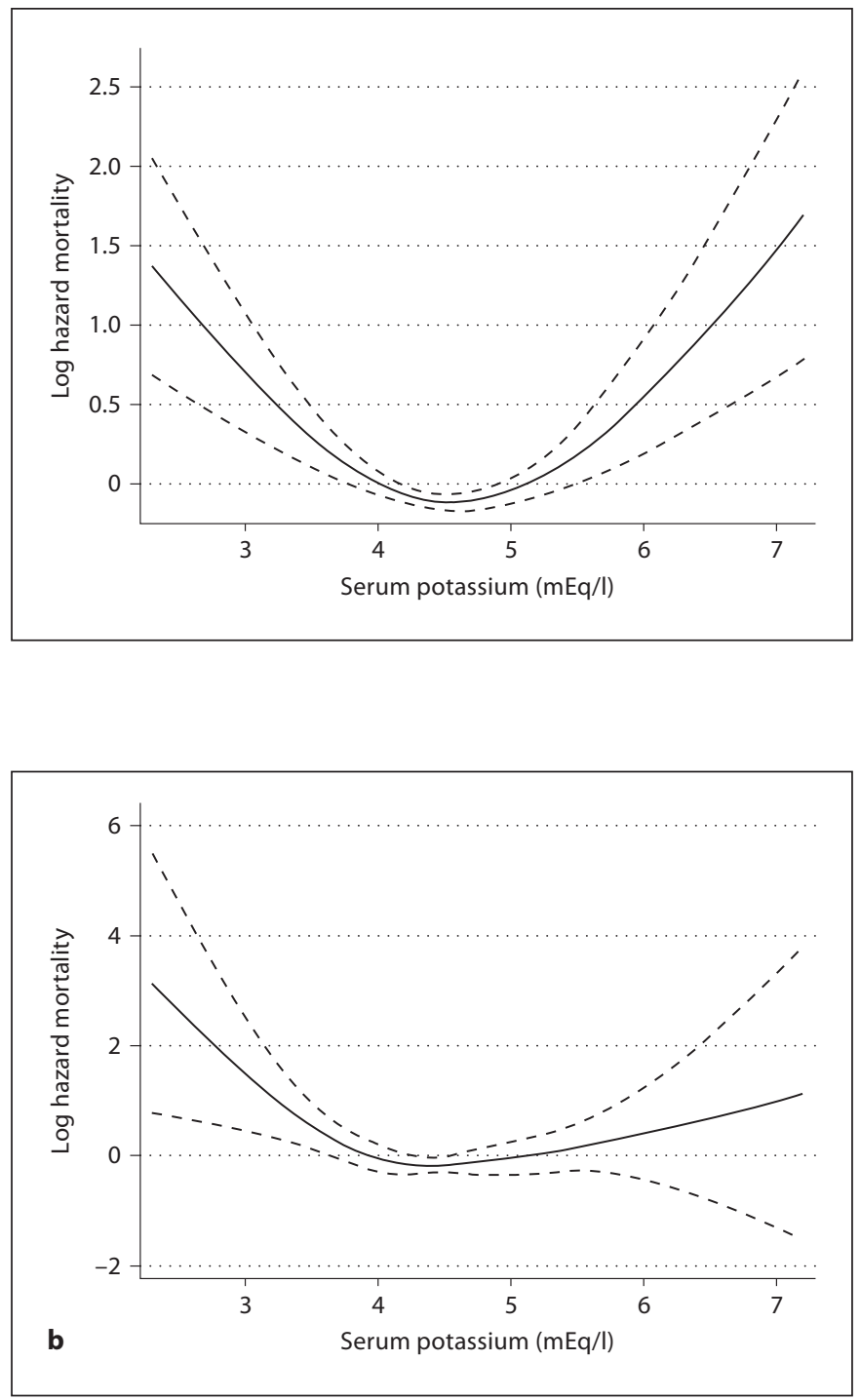

diovascular disease, BMI, the use of ACEI, ARBs, diuretics, potassium supplements, NSAIDs, beta-blockers, eGFR, serum albumin, bicarbonate, calcium, phosphorus, blood hemoglobin, and 24-hour urine protein.

( 81 of whom had a serum potassium $>5.5 \mathrm{mEq} / \mathrm{l}$ ) matched to black patients by potassium levels: multivariable adjusted hazard ratio $(95 \% \mathrm{CI})$ in whites with potassium $>5.5 \mathrm{vs}$. $3.8-5.5 \mathrm{mEq} / \mathrm{l}: 2.01(0.98-4.13), \mathrm{p}=0.057$.

The association between time-varying serum potassium level and slopes of eGFR in the overall study population was linear: a $1 \mathrm{mEq} / \mathrm{l}$ lower serum potassium was associated with a multivariable adjusted difference in slopes of eGFR of $-0.13 \mathrm{ml} / \mathrm{min} / 1.73 \mathrm{~m}^{2} /$ year (95\% CI: -0.20 to $-0.07), \mathrm{p}<0.001$. These associations were similar in sub- 


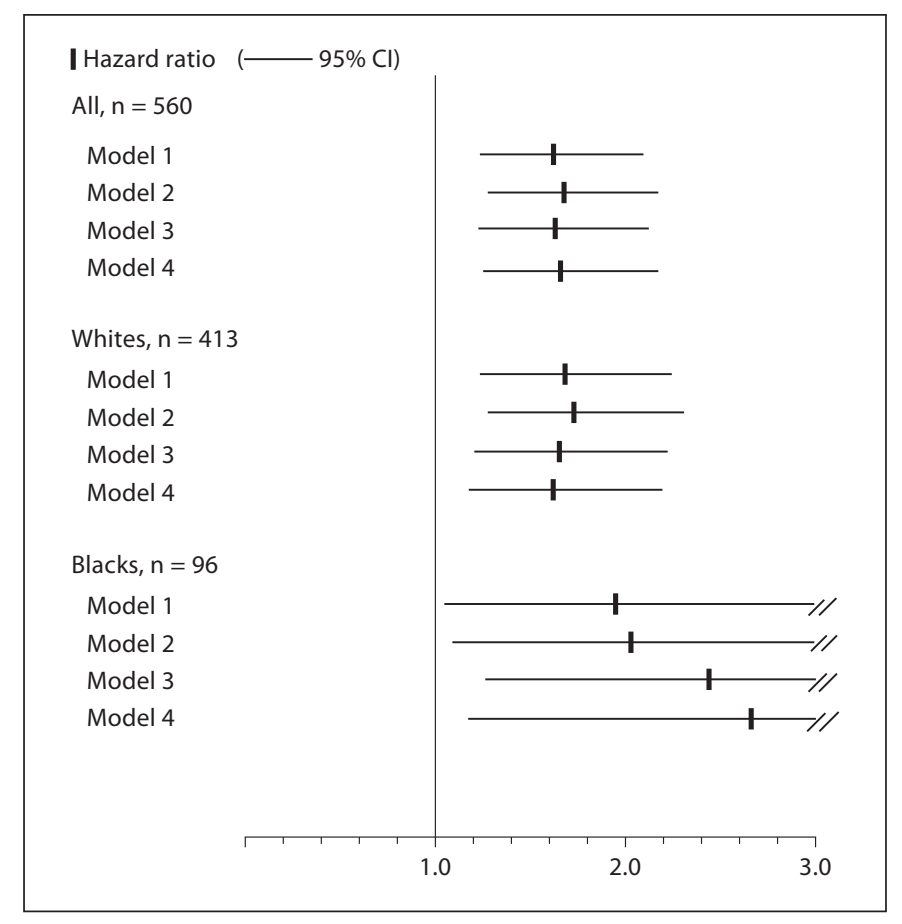

Fig. 3. Hazard ratios (95\% CI) of all-cause mortality associated with hypokalemia in time-dependent Cox models, overall and in white and black patients. Hypokalemia was defined as a serum potassium $<3.8 \mathrm{mEq} / \mathrm{l}$ in the overall group and in whites, and as a serum potassium $<3.7 \mathrm{mEq} / \mathrm{l}$ in blacks. The group with serum potassium 3.8-5.5 mEq/l served as referent in the overall group and in whites, and the group with serum potassium of 3.7-5.5 $\mathrm{mEq} / \mathrm{l}$ served as referent in blacks. Models represent unadjusted associations (model 1) and associations adjusted sequentially for age, race, smoking status, CCI, DM, cardiovascular disease and BMI (model 2), plus the use of ACEI, ARBs, diuretics, potassium supplements, NSAIDs, beta-blockers (model 3), plus eGFR, serum albumin, bicarbonate, calcium, phosphorus, blood hemoglobin, and 24-hour urine protein (model 4). N values represent the number of patients with hypokalemia in the respective groups.

groups of white patients $\left[-0.11 \mathrm{ml} / \mathrm{min} / 1.73 \mathrm{~m}^{2} /\right.$ year $(-0.19$ to -0.03$)], \mathrm{p}=0.005$, and black patients $[-0.17 \mathrm{ml} / \mathrm{min} / 1.73$ $\mathrm{m}^{2} /$ year $(-0.30$ to -0.05$\left.)\right], \mathrm{p}=0.007$. Categorical analyses indicated significantly steeper slopes of eGFR in patients with potassium $<3.6 \mathrm{mEq} / 1\left[-0.23 \mathrm{ml} / \mathrm{min} / 1.73 \mathrm{~m}^{2} /\right.$ year (95\% CI: -0.37 to -0.09 ), $\mathrm{p}=0.002$ compared to potassium 3.6-5.5], and no significant difference in patients with potassium $>5.5 \mathrm{mEq} / 1\left[0.03 \mathrm{ml} / \mathrm{min} / 1.73 \mathrm{~m}^{2} /\right.$ year $(95 \% \mathrm{CI}$ : -0.16 to 0.21$), \mathrm{p}=0.8$ compared to potassium $3.6-5.5$ ].

The results remained consistent in sensitivity analyses when deaths occurring after the initiation of dialysis were included in analyses, when the models were adjusted for systolic and diastolic blood pressure, when analyses were repeated using only unimputed values for the indepen-

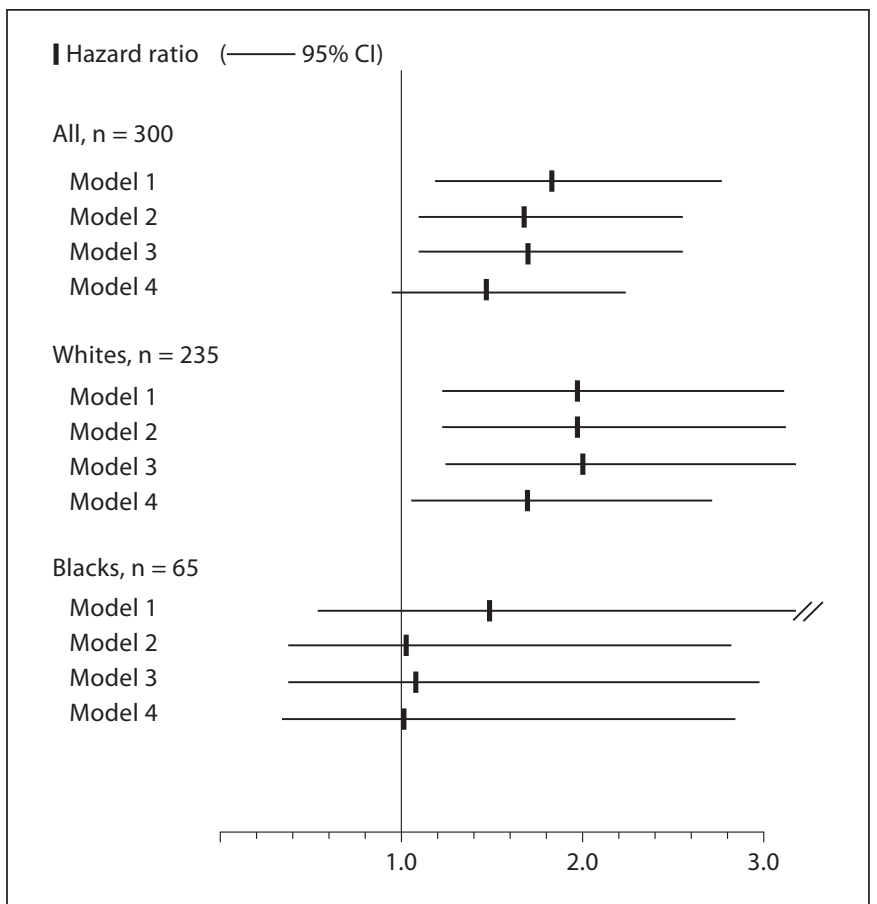

Fig. 4. Hazard ratios (95\% CI) of all-cause mortality associated with hyperkalemia in time-dependent Cox models, overall and in white and black patients. Hyperkalemia was defined as a serum potassium $>5.5 \mathrm{mEq} / \mathrm{l}$ in all three groups. The group with serum potassium 3.8-5.5 $\mathrm{mEq} / 1$ served as referent in the overall group and in whites, and the group with serum potassium of 3.7-5.5 $\mathrm{mEq} / 1$ served as referent in blacks. Models represent unadjusted associations (model 1) and associations adjusted sequentially for age, race, smoking status, CCI, DM, cardiovascular disease and BMI (model 2), plus the use of ACEI, ARBs, diuretics, potassium supplements, NSAIDs, beta-blockers (model 3), plus eGFR, serum albumin, bicarbonate, calcium, phosphorus, blood hemoglobin, and 24-hour urine protein (model 4). $\mathrm{N}$ values represent the number of patients with hyperkalemia in the respective groups.

dent variables, when medication exposure was included in multivariable analyses in non-time-dependent fashion, when the associations were examined in the subgroup of 259 patients who reached ESRD (for slopes only), or in a more contemporary cohort enrolled after January 1, 2001 (data not shown).

\section{Discussion}

We describe overall and race-specific characteristics of serum potassium, and their associations with relevant clinical characteristics, therapeutic interventions and clinical outcomes in patients with moderate and ad- 
vanced NDD-CKD. Overall mortality was significantly associated with both higher and lower serum potassium levels even after adjustments for relevant confounders. These associations were however different in the studied racial subgroups, as serum potassium $>5.5 \mathrm{mEq} / \mathrm{l}$ was significantly associated with mortality only in white patients, whereas potassium levels of $<3.8$ and $<3.7 \mathrm{mEq} / \mathrm{l}$ were associated with significantly higher mortality in white and black patients, respectively. Serum potassium $<3.6 \mathrm{mEq} / \mathrm{l}$ was associated with more pronounced progression of CKD in both races.

Both hypo- [2] and hyperkalemia [2,3] have been associated with an increase in mortality in patients on maintenance dialysis. Most recently, a large study that included patients with NDD-CKD also associated higher serum potassium levels with short-term mortality [4]. Such short-term effects on mortality could be explained by the electrophysiological role of potassium, and the increased arrhythmogenicity caused by both higher and lower serum potassium levels [27-29]. Another potential explanation is the confounding role of nutrition, as hypokalemia could be associated with malnutrition and hyperkalemia with harmful effects of high protein intake or hyperphosphatemia, even though the associations remained significant after adjustment for various nutritional markers in multivariable analyses.

To the best of our knowledge, ours is the first study to examine race-specific clinical outcomes associated with serum potassium levels. Studies in individuals with normal kidney function have examined race-specific potassium homeostasis in an attempt to find physiological explanations for the discrepant health outcomes seen in black vs. white patients. Black patients have been consistently found to have significantly lower urinary potassium excretion [14, 30-35]. One potential reason for this observation is the consumption by blacks of a diet that contains less potassium leading to a chronic potassiumdepleted state $[15,30,36]$, but the lower urinary excretion of potassium in blacks seemed to persist in studies that corrected for dietary differences by administering potassium supplements $[14,16,36]$ or when black and white participants were administered identical diets under controlled circumstances [15]. Further contradicting the notion that potassium depletion is solely responsible for the low urinary potassium excretion of blacks was a study showing that total body potassium is in fact higher in blacks on a free-living diet [37]. Other possible explanations invoke differences of potassium physiology in blacks, and include increased activity of the $\mathrm{Na}-\mathrm{K}-2 \mathrm{Cl}$ cotransporter in the thick ascending limb of the loop of
Henle [38], increased fecal excretion of potassium [33] and possibly differences in cellular potassium disposal [35]. It remains unclear how the aforementioned findings apply to patients with CKD, as similar comparative studies of potassium homeostasis have not been performed in this group. The potential presence of biological differences in potassium homeostasis in blacks vs. whites raises the possibility that the lack of association between hyperkalemia and mortality in blacks in our study may be related to more effective bodily defense mechanisms against higher serum potassium levels and/or its electrophysiological effects in these patients. A potential race-specific differential impact of hyperkalemia on clinical outcomes in NDD-CKD could be important, as better tolerance of elevated serum potassium levels could allow for more liberal application of treatments that elevate serum potassium levels (such as ACEI/ARB, aldosterone antagonists, or potassium-sparing diuretics) in black patients.

We also found that lower serum potassium levels were significantly associated with faster loss of kidney function over time, even after adjusting for other known risk factors such as blood pressure, proteinuria and comorbid conditions. A vacuolization of the proximal convoluted tubule accompanying chronic hypokalemia has indeed been described half a century ago [39]. This 'kaliopenic nephropathy' was thought to cause primarily impairment in concentrating ability, renal cyst formation and mild tubulointerstitial fibrosis [40-43]. Several case reports have also linked chronic potassium depletion to acute kidney injury, possibly because of coexisting volume depletion or rhabdomyolysis $[44,45]$, although direct adverse effects of hypokalemia on proximal tubular cells have also been implicated $[42,46]$. To our knowledge, prior to our study low potassium has not been described as a risk factor for progressive CKD. The proposed mechanism underlying the deleterious effects of lower potassium on kidney function includes direct tubulointerstitial injury via modulation of renal inflammation [6], local activation of the renin-angiotensin system [47], increased expression of angiotensin II receptors [48] or indirect effects through worsening hypertension. Another possible mechanism of action entails generation of excess ammonia in the proximal convoluted tubule in response to hypokalemia [49]. Acid-base imbalances can independently affect both serum potassium level and kidney function, and as such satisfy criteria for being a confounder [50] for the association between potassium level and kidney function. We adjusted for serum bicarbonate levels in our multivariate analyses to address this, and found that the association remained significant, indicating the possible role of other mechanisms of action. 
Animal studies have shown that potassium supplementation can mitigate renal injury $[8,51,52]$, suggesting a causal role for low potassium in progressive CKD. The low cost and the ease with which potassium depletion can be corrected should prompt efforts to delineate the role of hypokalemia correction as part of multipronged efforts to slow the progression of CKD.

Our study has several limitations. The retrospective and observational nature of our analyses allows for the detection of associations, but does not prove causality. We examined male patients at a single medical center; thus, our results may not apply to the CKD population at large, especially females. Relatively few patients experienced abnormally high or low serum potassium levels; hence, it is possible that the lack of significant association with mortality in blacks with hyperkalemia was due to a lower statistical power. Differences between blacks and whites persisted, however, after limiting analyses to an equally low number of white patients matched to blacks by potassium levels, suggesting that such differences may not have been solely due to the low number of participants involved. We examined patients enrolled over an extended period of time; thus, temporal changes in clinical practice could have biased our results. To address this shortcoming, we examined separately patients enrolled more recently and found consistent results. We were able to account for the potential effect of a multitude of confounding variables, but residual confounding may still be present. One such important factor is the exclusion of serum potassium values that were measured during inpatient hospitalizations, which limits our ability to extend our findings to patients who develop abnormal serum potassium levels while hospitalized. However, a recent study examining the associations between serum potassium and 1-day mortality found similar associations between higher serum potassium and outcomes in inpatients vs. outpatients [4]. We adjusted for the confounding effect of medications, but some of these medications might have been changed as a result of changes in serum potassium levels. To account for this, we performed analyses where we considered the use of medications such as ACEI/ARB in a non-timevarying fashion, which did not change our results. We did not record the use of potassium-sparing diuretics, which could have affected both serum potassium levels and mortality outcomes especially in patients with coexisting congestive heart failure. However, we do not expect that a significant number of patients would have received such diuretics, given the nature of this population (moderate and advanced CKD under the care of nephrologists). We did not have information about the presence/absence of congestive heart failure, or about the doses of the diuretics administered, which could also have confounded the reported associations. We hypothesized that cardiovascular events could have been the reason for the observed association between serum potassium and all-cause mortality, but we did not have causes of deaths available for analysis in order to test this hypothesis.

\section{Conclusions}

Both high and low serum potassium are associated with increased mortality in male patients with NDD$\mathrm{CKD}$, but this association varies by race, with only white patients showing a consistent association between hyperkalemia and increased mortality. Low potassium is associated with higher mortality and with significantly more severe progression of CKD both in white and in black patients. If confirmed by prospective studies, these results suggest that interventions aimed at the maintenance of ideal serum potassium levels (through proactive screening to detect abnormal levels and through various interventions aimed at correcting such levels) could be beneficial in lowering mortality and in slowing progression of CKD in this patient population. Further studies are needed to clarify the reasons behind potential race-specific differences in potassium's association with mortality and to determine what interventions directed at normalizing serum potassium could offer the most benefit.

\section{Acknowledgements}

Parts of this material were presented at the American Society of Nephrology Renal Week 2009, October 27 to November 1, 2009, San Diego, Calif., USA. This study was supported by grant 1R01DK078106-01 (C.P.K. and K.K.-Z.) and by the US Department of Veterans Affairs (C.P.K.). C.P.K. is an employee of the US Department of Veterans Affairs.

\section{Disclosure Statement}

None of the authors declare any competing financial interests. 
3 Iseki K, Uehara H, Nishime K, et al: Impact of the initial levels of laboratory variables on survival in chronic dialysis patients. Am J Kidney Dis 1996;28:541-548.

4 Einhorn LM, Zhan M, Hsu VD, et al: The frequency of hyperkalemia and its significance in chronic kidney disease. Arch Intern Med 2009;169:1156-1162.

5 Tannen RL: The influence of potassium on blood pressure. Kidney Int Suppl 1987; 22:S242-S248.

6 Wang W, Soltero L, Zhang P, et al: Renal inflammation is modulated by potassium in chronic kidney disease: possible role of Smad7. Am J Physiol Renal Physiol 2007; 293:F1123-F1130.

7 Oberleithner H, Callies C, Kusche-Vihrog K, et al: Potassium softens vascular endothelium and increases nitric oxide release. Proc Natl Acad Sci USA 2009;106:2829-2834.

8 Pere AK, Krogerus L, Mervaala EM, et al: Beneficial effects of dietary magnesium and potassium on cardiac and renal morphologic features in cyclosporin A-induced damage in spontaneously hypertensive rats. Surgery 2000;128:67-75.

9 Ishimitsu T, Tobian L, Sugimoto K, et al: High potassium diets reduce macrophage adherence to the vascular wall in strokeprone spontaneously hypertensive rats. J Vasc Res 1995;32:406-412.

10 Ishimitsu T, Tobian L, Sugimoto K, et al: High potassium diets reduce vascular and plasma lipid peroxides in stroke-prone spontaneously hypertensive rats. Clin Exp Hypertens 1996;18:659-673.

11 Brancati FL, Appel LJ, Seidler AJ, et al: Effect of potassium supplementation on blood pressure in African Americans on a low-potassium diet. A randomized, double-blind, placebo-controlled trial. Arch Intern Med 1996;156:61-67.

12 Morris RC Jr, Sebastian A, Forman A, et al: Normotensive salt sensitivity: effects of race and dietary potassium. Hypertension 1999; 33:18-23.

13 Grim CE, Luft FC, Miller JZ, et al: Racial differences in blood pressure in Evans County, Georgia: relationship to sodium and potassium intake and plasma renin activity. J Chronic Dis 1980;33:87-94.

14 Langford HG, Cushman WC, Hsu H: Chronic effect of $\mathrm{KCl}$ on black-white differences in plasma renin activity, aldosterone, and urinary electrolytes. Am J Hypertens 1991;4: 399-403.

15 Luft FC, Rankin LI, Bloch R, et al: Cardiovascular and humoral responses to extremes of sodium intake in normal black and white men. Circulation 1979;60:697-706.

16 Wong CM, O'Connor DT, Martinez JA, et al: Diminished renal kallikrein responses to mineralocorticoid stimulation in African Americans: determinants of an intermediate phenotype for hypertension. Am J Hypertens 2003;16:281-289.

17 Cohen SL, Jhetam D, Da SJ, et al: Sodium and potassium status, plasma renin and aldosterone profiles in normotensive and hyperten- sive Johannesburg blacks. S Afr Med J 1982; 62:941-944.

18 Easterling RE: Racial factors in the incidence and causation of end-stage renal disease (ESRD). Trans Am Soc Artif Intern Organs 1977;23:28-33.

19 Rostand SG, Kirk KA, Rutsky EA, et al: Racial differences in the incidence of treatment for end-stage renal disease. N Engl J Med 306;1982:1276-1279.

20 Kalantar-Zadeh K, Kovesdy CP, Derose SF, et al: Racial and survival paradoxes in chronic kidney disease. Nat Clin Pract Nephrol 2007; 3:493-506.

21 Kovesdy CP, Anderson JE, Derose SF, et al: Outcomes associated with race in males with nondialysis-dependent chronic kidney disease. Clin J Am Soc Nephrol 2009;4:973-978

22 Kovesdy CP, Trivedi BK, Anderson JE: Association of kidney function with mortality in patients with chronic kidney disease not yet on dialysis: a historical prospective cohort study. Adv Chronic Kidney Dis 2006;13: 183-188.

23 Kovesdy CP, Trivedi BK, Kalantar-Zadeh K, et al: Association of low blood pressure with increased mortality in patients with moderate to severe chronic kidney disease. Nephrol Dial Transplant 2006;21:1257-1262.

24 Levey AS, Bosch JP, Lewis JB, et al: A more accurate method to estimate glomerular filtration rate from serum creatinine: a new prediction equation. Ann Intern Med 1999; 130:461-470.

25 Singer JD, Willett JB: Applied Longitudinal Data Analysis. Modeling Change and Event Occurrence. Oxford, Oxford University Press, 2003.

26 Royston P, Sauerbrei W: Multivariable modeling using cubic regression splines: a principled approach. Stata J 2007;7:45-70.

27 Epstein FH: Signs and symptoms of electrolyte disorders; in Maxwell MH, Kleeman CR (eds): Clinical disorders of fluid and electrolyte metabolism, ed 3. New York, McGrawHill, 1980, p 145.

28 Fisch C: Electrolytes and the heart; in Hurst JW (ed): The Heart. New York, McGrawHill, 1982, p 1599

29 Kleeman K, Singh BN: Serum electrolytes and the heart; in Maxwell MH, Kleeman CR (eds): Clinical Disorders of Fluid and Electrolyte Metabolism, ed 3. New York, McGraw-Hill, 1980, p 145.

30 Turban S, Miller ER III, Ange B, et al: Racial differences in urinary potassium excretion. J Am Soc Nephrol 2008;19:1396-1402.

31 Aviv A, Hollenberg NK, Weder A: Urinary potassium excretion and sodium sensitivity in blacks. Hypertension 2004;43:707-713.

32 Urinary and serum electrolytes in untreated black and white hypertensives. Veterans Administration Cooperative Study Group on Antihypertensive Agents. J Chronic Dis 1987;40:839-847.

33 Barlow RJ, Connell MA, Milne FJ: A study of 48-hour faecal and urinary electrolyte excretion in normotensive black and white South African males. J Hypertens 1986;4:197-200.
34 Taylor EN, Curhan GC: Differences in 24hour urine composition between black and white women. J Am Soc Nephrol 2007;18: 654-659.

35 Suh A, DeJesus E, Rosner K, et al: Racial differences in potassium disposal. Kidney Int 2004;66:1076-1081.

36 Voors AW, Dalferes ER Jr, Frank GC, et al: Relation between ingested potassium and sodium balance in young Blacks and whites. Am J Clin Nutr 1983;37:583-594.

$37 \mathrm{He} \mathrm{Q}, \mathrm{Heo} \mathrm{M}$, Heshka S, et al: Total body potassium differs by sex and race across the adult age span. Am J Clin Nutr 2003;78:72-77.

38 Luft FC, Grim CE, Fineberg N, et al: Effects of volume expansion and contraction in normotensive whites, blacks, and subjects of different ages. Circulation 1979;59:643-650.

39 Conn JW, Johnson RD: Kaliopenic nephropathy. Am J Clin Nutr 1956;4:523-528.

40 Elger M, Bankir L, Kriz W: Morphometric analysis of kidney hypertrophy in rats after chronic potassium depletion. Am J Physiol 1992;262:F656-F667.

41 Torres VE, Young WF Jr, Offord KP, et al: Association of hypokalemia, aldosteronism, and renal cysts. N Engl J Med 1990;322:345351.

42 Cremer W, Bock KD: Symptoms and course of chronic hypokalemic nephropathy in man. Clin Nephrol 1977;7:112-119.

43 Riemenschneider T, Bohle A: Morphologic aspects of low-potassium and low-sodium nephropathy. Clin Nephrol 1983;19:271-279.

44 Copeland PM: Renal failure associated with laxative abuse. Psychother Psychosom 1994; 62:200-202.

45 Wright LF, DuVal JW Jr: Renal injury associated with laxative abuse. South Med J 1987; 80:1304-1306.

46 Menahem SA, Perry GJ, Dowling J, et al: Hypokalaemia-induced acute renal failure. Nephrol Dial Transplant 1999;4:2216-2218.

47 Ray PE, Suga S, Liu XH, et al: Chronic potassium depletion induces renal injury, salt sensitivity, and hypertension in young rats. Kidney Int 2001;59:1850-1858.

48 Fryer JN, Burns KD, Ghorbani M, et al: Effect of potassium depletion on proximal tubule AT1 receptor localization in normal and remnant rat kidney. Kidney Int 2001;60: 1792-1799.

49 Tolins JP, Hostetter MK, Hostetter TH: Hypokalemic nephropathy in the rat. Role of ammonia in chronic tubular injury. J Clin Invest 1987;79:1447-1458.

50 Jager KJ, Zoccali C, Macleod A, Dekker FW: Confounding: what it is and how to deal with it. Kidney Int 2008;73:256-260.

51 Pere AK, Lindgren L, Tuomainen P, et al: Dietary potassium and magnesium supplementation in cyclosporine-induced hypertension and nephrotoxicity. Kidney Int 2000; 58:2462-2472.

52 Tobian L, MacNeill D, Johnson MA, et al: Potassium protection against lesions of the renal tubules, arteries, and glomeruli and nephron loss in salt-loaded hypertensive Dahl S rats. Hypertension 1984;6:I170-I176. 